\title{
Dispersion of organophilic Ag nanoparticles in PS-PMMA blends
}

\author{
Şeyda Tüzüner, Mustafa M. Demir* \\ Department of Materials Science and Engineering, İzmir Institute of Technology, 35430 Gülbahçe, Urla, İzmir, Turkey
}

\section{H I G H L I G H T S}

- Ag nanoparticles were obtained throughout a redox reaction.

- Electrostatically stabilized particles were capped by CTAB.

- The organophilic particles were added into PS and PMMA blend system.

- The placement of the $\mathrm{Ag}$ particle domains was readily controlled.

- The amount of CTAB and post treatment of the composites were system parameters.

\section{A R T I C L E I N F O}

\section{Article history:}

Received 29 January 2015

Received in revised form

16 June 2015

Accepted 20 June 2015

Available online 2 July 2015

\section{Keywords:}

Interfaces

Heterostructures

Polymers

Surface properties
G R A P H I C A L A B S T R A C T

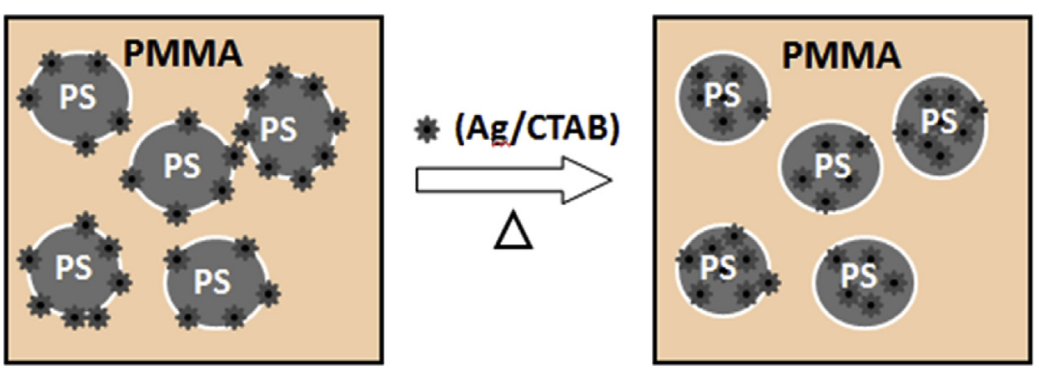

\begin{abstract}
A B S T R A C T
The preparation of stable composites with well-controlled particle location is one of the challenges in formulating new polymer/nanoparticle mixtures. In this study, cetyltriammonium bromide (CTAB)capped monodisperse Ag nanoparticles were prepared and mixed with an equimass blend of polystyrene (PS) and poly(methyl methacrylate) (PMMA) in solution. The surface of the blend film without nanoparticles showed spherical pits with a size of $4.5 \mu \mathrm{m}$ in diameter. The integration of CTAB-capped nanoparticles into the blend film developed surface bumps with a size of $0.4 \mu \mathrm{m}$ in diameter. The organophilic Ag nanoparticles were distributed heterogeneously in the immiscible PS-PMMA blend. When the diameter of particle domains reached approximately $20 \mathrm{~nm}$, particles were preferentially located at the interface of the PS and PMMA domains. Larger particle domains with a diameter of $90 \mathrm{~nm}$ were found to be in the PMMA-rich phase. Isothermal post-treatment of the PS-PMMA/Ag composite films directs the particle domains into PS domains. Thermodynamic factors that contribute to the observed morphologies are discussed.
\end{abstract}

(C) 2015 Elsevier B.V. All rights reserved.

\section{Introduction}

The association of nanoparticles with a polymer blend offers significant features beyond the advantages of polymer composites prepared with a single homopolymer. From the structural point of view, the particles are randomly dispersed in the homopolymer matrix [1]. The particles can be organized in multiphase polymeric

\footnotetext{
* Corresponding author.

E-mail address: mdemir@iyte.edu.tr (M.M. Demir).
}

matrix systems, such as in homopolymer blends or block copolymers, since phase separation of the systems produces nanoand microdomains on large areas and in a scalable fashion [2,3]. Applications include instances where particle ordering is required, such as plasmonic waveguides, plasmonic photocrystals, and sensors [3]. The location of the nanoparticles depends on a delicate balance of thermodynamic functions, both enthalpy and entropy. The former refers to polymer-ligand interaction between the particle surface and surrounding polymer matrix chains. The functionalized nanoparticles can interact favorably with a specific polymer component and can be preferentially located in its 
corresponding domains. Conversely, the latter refers to conformational loss of the matrix chains. The incorporation of the solid inorganic nanoparticles into flexible polymers causes stretching of the chains. When a chain is stretched, the entropy reduces due to fewer available confirmations. In addition, the arrangement of particle domains in a polymer matrix, i.e., the level of particle dispersion, also contributes to the entropy of the system.

A blend of polystyrene (PS) and poly(methyl methacrylate) (PMMA) is an ideal and attractive system for studying phase separation [4]. These blends have been intensively studied over the past two decades and allow the formation of complex layered or lateral micro- or nanoscale structures [5]. For instance, Huang et al. prepared a spin-coat film of PS-PMMA with a pitted surface morphology [6]. The continuous PMMA phase was selectively dissolved and the remaining PS pits were used as a lift-off mask for the formation of a nanopatterned functional silane monolayer. The application of the blend films in lithography was shown. On the other hand, Ag nanoparticles are optically active materials and have been widely used in various applications such as data storage [7], photonics [8], and plasmonic devices [9]. The collective response of conduction band electrons (surface plasmons) causes a strong absorption in the UV-Vis spectral region that can be readily tuned by the size and shape of the Ag nanoparticles. Moreover, the particles can exhibit strong photostimulated luminescence, showing very short picosecond life times. Authors suggested that $\mathrm{Ag}$ and $\mathrm{Ag}$ halide particles may have potential for applications in microbiology $[10,11]$, digital storage [11], and as antibacterial agents [12]. The combination of [CTAB]-capped Ag particles and PS and PMMA allows the formation of novel microstructural materials with particle ordering.

PS and PMMA blend systems associated with various nanoparticles have been previously reported. Chung et al. reported the directed interfacial segregation of silica nanoparticles in PMMA/ poly(styrene-ran-acrylonitrile) with different particle contents [13]. The authors proposed a simple interfacial energy argument to act as a guideline for predicting whether the nanoparticles are directed to the interface between the phases or into the phase preventing film rupture. Xiu et al. studied phase morphology in compounded hydrophilic silica nanoparticles in polylactide/poly(ether)urethane blend films [14]. The selective location of silica nanoparticles in the polyurethane phase and at the phase interface induces the morphological change from a common sea-island structure to a unique network structure, thus giving rise to remarkable improvement in the impact toughness. Cai et al. attempted to clarify the effect of the nanoparticle selfagglomeration structure on the morphology of PS/polyamide blends in the presence of $\mathrm{TiO}_{2}$ nanoparticles [15]. It was found that the nanoparticles tended to form separate compact clusters in the polyamide phase and a completely different coagulation pattern as compared to other fillers such as carbon black due to its higher surface energy. Apart from blends, this phenomenon of selective loading has also been reported for block copolymers. As example, various types of $\mathrm{SiO}_{2}$ [16], $\mathrm{Au}$ [17], $\mathrm{BaTiO}_{3}$ [18], $\mathrm{TiO}_{2}$ [19], $\mathrm{Fe}_{3} \mathrm{O}_{4}$ [20], and CdSe [21] nanoparticles were employed in a PS-b-PMMA matrix.

It is well established that to localize particles within the A- or Bdomain in polymer blends or block copolymers, the particles need to be coated with homopolymer A or B, respectively [22]. However, the coating of nanoparticles with homopolymer requires precise control over both polymer molecular weight and the end group to be used for the immobilization to the particle surface. Surface capping of particles by straightforward commercial capping agents, which have favorable interactions with one of the phases in blends, can simplify the selective loading process. In this study, Ag nanoparticles were synthesized and capped by CTAB. The organophilic particles were associated with PS and PMMA blends in tetrahydrofuran (THF) solution. The effects of the amount of CTAB employed in surface functionalization and isothermal heat treatment were examined as the system parameters. The placement of the nanoparticles was studied using atomic force microscopy (AFM).

\section{Experimental work}

\subsection{Chemicals}

Sodium borohydride $\left(\mathrm{NaBH}_{4}\right.$; Sigma-Aldrich, 99.99\%), silver nitrate $\left(\mathrm{AgNO}_{3}\right.$; Alfa Aesar, $\left.+99 \%\right)$, PS (Aldrich Chemical Co., $M_{w}$ 350,000), PMMA (Aldrich Chemical Co., $M_{w} \sim 15,000$ ), tetrahydrofuran (THF; VWR International), and CTAB (Sigma-Aldrich) were used as obtained without further purification.

\subsection{Preparation of PS-PMMA/Ag composites}

A two-step process was applied for the synthesis of organophilic $\mathrm{Ag}$ nanoparticles. In the first step, naked $\mathrm{Ag}$ nanoparticles were obtained via a redox reaction occurring between $\mathrm{NaBH}_{4}$ and $\mathrm{AgNO}_{3}$ [23]. A $10 \mathrm{~mL}$ aliquot of $0.01 \mathrm{M} \mathrm{AgNO}_{3}$ was added dropwise (about 1 drop s${ }^{-1}$ ) to $30 \mathrm{~mL}$ of $0.02 \mathrm{M} \mathrm{NaBH}_{4}$ solution that had been chilled in an ice bath. The reaction mixture was stirred vigorously on a magnetic plate. The redox reaction can be represented as follows:

$2 \mathrm{AgNO}_{3}+\mathrm{NaBH}_{4} \rightarrow 2 \mathrm{Ag}^{\circ}+\mathrm{BH}_{3}+\mathrm{HNO}_{3}+\mathrm{NaNO}_{3}$

CTAB was used for the surface modification at two different concentrations in water: $0.02 \mathrm{M}$ and $0.002 \mathrm{M}$. CTAB solution was added to the dispersion of silver nanoparticles in a 1:20 ratio $(1 \mathrm{~mL}$ of CTAB for $40 \mathrm{~mL}$ of silver nanoparticle dispersion). After addition of $C T A B$, the dispersion turned black and was sonicated until the CTAB dissolved in the solution. A drop of dispersion was cast on cupper grid of TEM. After the evaporation of the solvent, the surface of the grid was scanned by microscopy. The final solution was then centrifuged at $6000 \mathrm{rpm}$ for $40 \mathrm{~min}$. Polymer blend solutions were prepared by dissolving PS and PMMA in a 1:1 weight ratio in THF at $2.5 \%(\mathrm{w} / \mathrm{v})$. After the complete dissolution of both homopolymers, the powder of CTAB capped the Ag nanoparticles was redispersed into the polymer solution mixture. PS-PMMA/Ag nanocomposite films were prepared by casting the dispersion mixture on a glass surface. The thickness of the films was between 2 and $4 \mu \mathrm{m}$. The concentration of the particles with respect to polymer was fixed at 0.7 wt.\%.

\subsection{Characterization tools}

Transition electron microscopy (TEM) was performed using a Zeiss EM 902 (Zeiss International, Göttingen, Germany). Dynamic light scattering (DLS; Malvern Zetasizer Nano-ZS Nano Series, Malvern Instruments, Malvern, UK) was used to measure the size distributions of the particles and surface charge. Using nuclear magnetic resonance (NMR; Varian $400 \mathrm{MHz}$, Varian, Palo Alto, CA, USA), surfactant molecules were identified on the surface of the nanoparticles in deuterated dimethyl sulfoxide (DMSO). Thermal gravimetric analysis of the samples was applied from $0{ }^{\circ} \mathrm{C}$ to $600{ }^{\circ} \mathrm{C}$ with air and a PerkinElmer Diamond TG/DTA (PerkinElmer, Waltham, MA, USA). Differential scattering calorimetry (DSC Q10 V9.4 Build 287, TA Instruments, New Castle, DE, USA) was used to measure the glass transition temperature of thin films and was applied from $25^{\circ} \mathrm{C}$ to $160{ }^{\circ} \mathrm{C}$ under $\mathrm{N}_{2}$ gas with a $50.0 \mathrm{~mL} / \mathrm{min}$ flow rate and an aluminum pan. Nanoscope IV (Digital Instruments, Tonawanda, NY, USA) was employed for AFM imaging using the 
tapping mode of silicon tip. Energy dispersive X-ray spectroscopy (Quanta 250 scanning electron microscope, FEI, Hillsboro, OR, USA) was used for elemental analysis and to identify particular elements and their relative proportions in the sample (atomic \%). UV-Vis spectroscopy (Shimadzu UV 2550, Shimadzu, Kyoto, Japan) was employed in the range of $200-800 \mathrm{~nm}$ for absorption.

\section{Results and discussion}

\subsection{Synthesis of Ag nanoparticles}

Fig. 1a presents a representative overview TEM image of the $\mathrm{Ag}$ particles. When the reaction between $\mathrm{AgNO}_{3}$ and $\mathrm{NaBH}_{4}$ was completed, a drop of reaction mixture was cast on TEM grid. The evaporation of solvent left behind $\mathrm{Ag}$ particles and they were probed by electron beam. The particles on the grid appeared as spherical and nonaggregated islands. A higher magnification image of the particles showed a distribution of particle diameter measured from the TEM image in Fig. 1b. Statistical analysis of the particles in TEM images showed that they have a diameter of $6 \mathrm{~nm}$ on average (Fig. 1c). Fig. 1d illustrates the electron diffraction pattern of an individual particle. The discrete sharp circles assigned with the planes are the fingerprint of the crystalline nature of the silver nanoparticle. Fig. 2 illustrates DLS number size distribution of the particles in dispersion before and after the surface capping process. The measurements were obtained in water and THF for both naked and CTAB-capped $\mathrm{Ag}$ particles, respectively. The mean

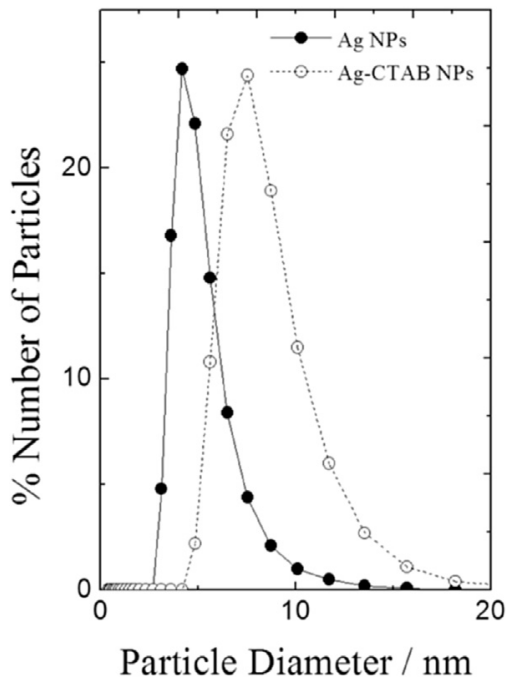

Fig. 2. DLS number size distribution of the $\mathrm{Ag}$ and $\mathrm{CTAB}$ capped $\mathrm{Ag}$ particles.

diameter of the naked particles was found to be almost identical to the size measured by microscopy. When the particles were capped by CTAB, the size increased to $9 \mathrm{~nm}$. The increase in particle size can be attributed to the immobilization of the surfactant molecule. As a matter of fact, the length of the surfactant was estimated to be
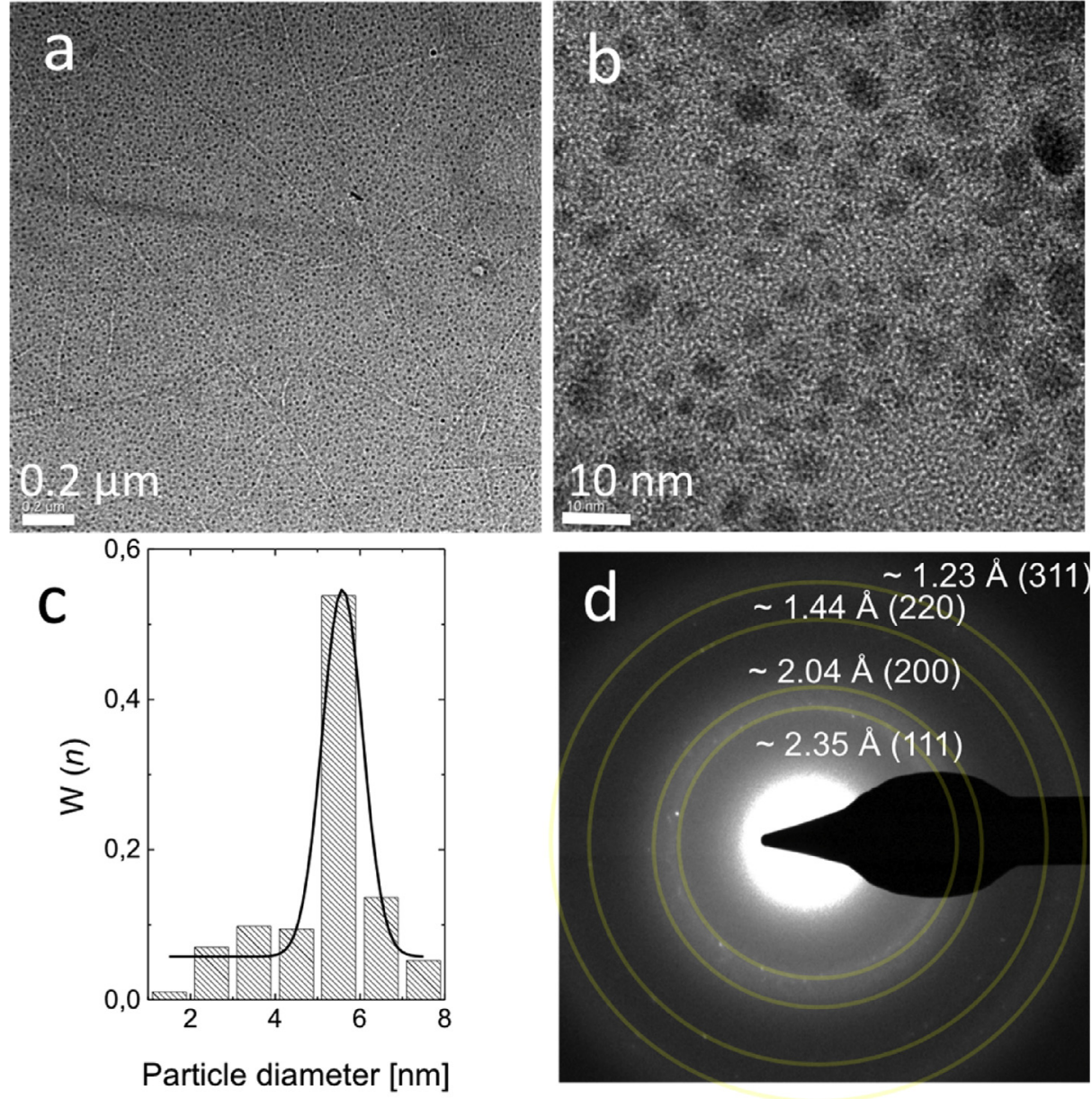

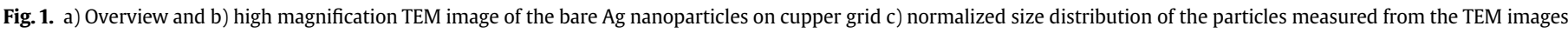
d) electron diffraction pattern of the Ag particles. 
approximately $1.5 \mathrm{~nm}$. CTAB molecules on the surface of the $\mathrm{Ag}$ nanoparticles were also validated by NMR spectroscopy. Chemical shifts of Ag particles and CTAB-capped Ag particles are presented in Fig. 3. Bare Ag particles did not show any signal except the ones of DMSO (solvent) and of $\mathrm{H}_{2} \mathrm{O}$ in the solvent at 3.32 and $2.50 \mathrm{ppm}$, respectively. When $\mathrm{CTAB}$ immobilized to the particle surface, characteristic signals of CTAB appeared. For instance, $-\mathrm{CH}_{3}$ signal attached to nitrogen atom at $3.0 \mathrm{ppm}$ and $-\mathrm{CH}_{2}$ signal at $1.22 \mathrm{ppm}$. In addition, multiplet feature of $\mathrm{H}-\mathrm{H}$ coupling of $\alpha-\mathrm{CH}_{2}$ at $0.86 \mathrm{ppm}$ and $\beta-\mathrm{CH}_{2}$ signal at $1.75 \mathrm{ppm}$ indicated successful immobilization of the CTAB molecule to the particle surface. This result is compatible with the literature [24]. The surface capping process was also observed by zeta potential measurement employing DLS. Fig. 4 shows zeta potential of the naked $\mathrm{Ag}$ nanoparticles and $\mathrm{Ag}$ nanoparticles capped with CTAB. The surface charge of the naked $\mathrm{Ag}$ particles is around $-47 \mathrm{mV}$. This negative charge on the particles may originate from $\mathrm{BH}_{4}^{-}$ions inevitably coming from the reducing agent, $\mathrm{NaBH}_{4}$. The particles repel each other such that they are electrostatically stabilized; aggregation of the particles is thereby prevented. After the capping process, an electrostatic interaction takes place between the particle surface and CTAB. The surface charge of particle was found to be $+34 \mathrm{mV}$. The quaternary ammonium salt molecules may cap the majority of the negative center on the particle's surface. The Ag particles are now sterically stabilized by long cetyl chains, which prevented the particles from getting close in the range of attractive forces (Scheme 1). Pictures of the Ag particle dispersions and absorbance of light are shown in Fig. 5. Yellow dispersion refers to $\mathrm{Ag}$ nanoparticles and black to CTAB-capped Ag nanoparticles. The spectra show the difference between the particles before and after capping with CTAB. The naked particles have a sharp signal centered at $400 \mathrm{~nm}$. Upon capping the particles with CTAB, a shoulder around $450 \mathrm{~nm}$ appears separate from the main signal. This new signal can be attributed to the presence of agglomerated Ag particles [23,25]. The occurrence of large agglomerates after the capping process shows that steric stabilization of the particles by CTAB is not as effective as electrostatic stabilization of the naked particle. Surface capping of the nanoparticles was carried out at two different CTAB concentrations: $0.020 \mathrm{M}$ and $0.002 \mathrm{M}$. Elemental analysis on particle surface was performed using energy dispersive spectroscopy on the particle

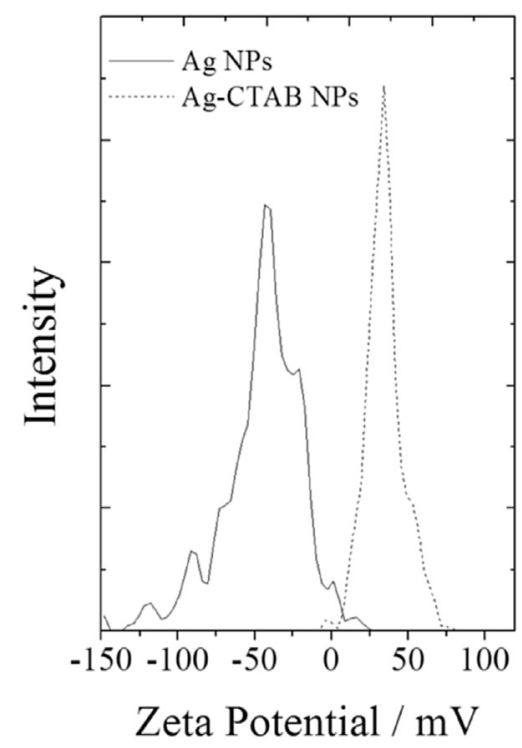

Fig. 4. Surface potential of the bare and CTAB-capped Ag particles.

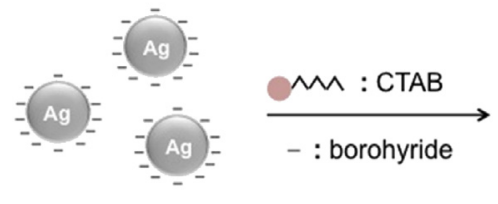

Electrostatic stabilization

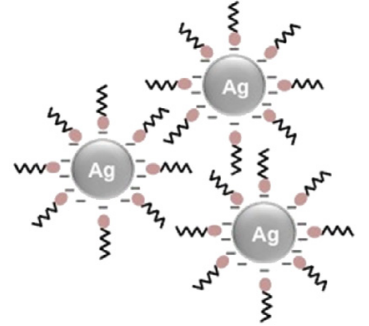

Steric stabilization
Scheme 1. Schematic view of electrostatic and steric stabilization of the $\mathrm{Ag}$ nanoparticles.

surface. While the weight percentage of $\mathrm{N}$ is $4.22 \%$ for the $\mathrm{Ag}$ nanoparticles capped with $0.002 \mathrm{M} \mathrm{CTAB}$, the percentage increases to $6.95 \%$ for the Ag nanoparticles capped with $0.02 \mathrm{M}$ CTAB. Not

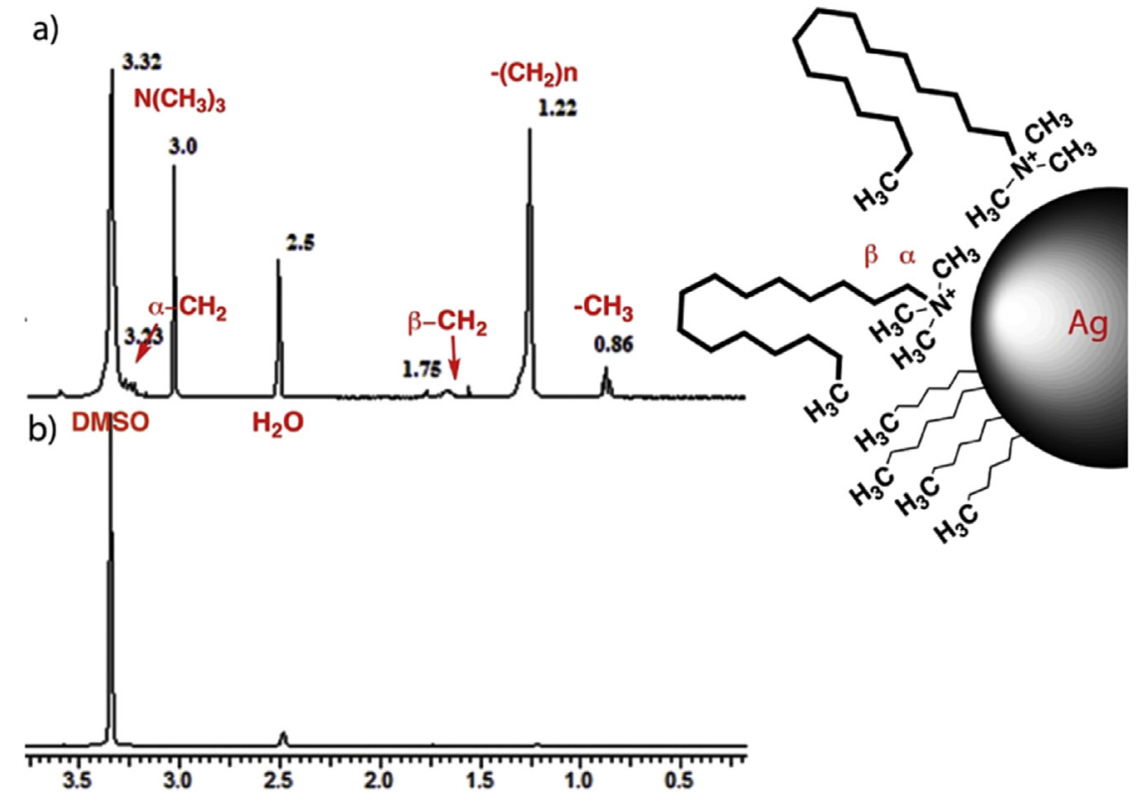

Fig. 3. NMR spectra for the bare (a) and CTAB capped Ag nanoparticles (b). 


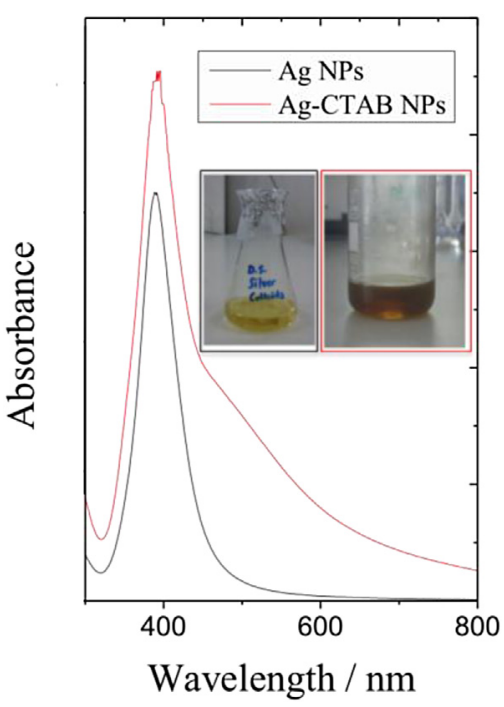

Fig. 5. Absorption spectra of the bare Ag particles (yellow dispersion) and CTABcapped $\mathrm{Ag}$ nanoparticles (black dispersion). (For interpretation of the references to colour in this figure legend, the reader is referred to the web version of this article.)

surprisingly, increasing the concentration of CTAB increases the nitrogen content and accordingly, the grafting density of the capping agent on the particle surface. The amount of capping agent on the particle surface determines the size and the location of the particle domains in PS-PMMA blends, which will be addressed in later stages of the text.

\subsection{Synthesis of PS-PMMA and Ag-CTAB nanoparticle composite}

Phase separation of the two immiscible homopolymers allows the structuring and patterning of surfaces with a lateral resolution down to the submicron/micrometer scale. AFM technique allows not only the imaging of surface topography of surfaces, but also the spatially resolved study of phase behavior. The film of the homopolymer, either PS or PMMA, exhibits a flat surface that is free of features (Figure S1). High-resolution images with high contrast between the PS-rich and the PMMA-rich phases can be obtained. Fig. 6 presents tapping-mode AFM images of the PS-PMMA blend prepared at a $1: 1$ ratio by mass. The topography shows a pitted surface in accordance with literature [26]. The reason could be the formation of a breath figure, i.e. condensation of water droplets during evaporative cooling of moisture. The pits have a disc-like morphology of the shape at nearly $4.5 \mu \mathrm{m}$ in diameter and $0.2 \mu \mathrm{m}$ in depth. They seem homogeneously dispersed throughout

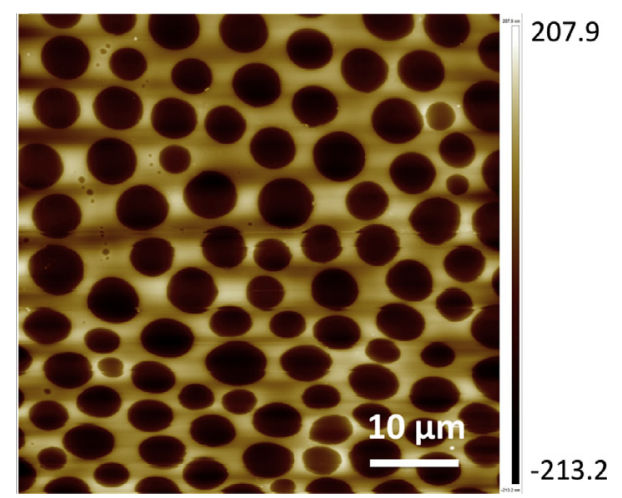

Fig. 6. A representative tapping mode AFM image of equimass blend film of PS and PMMA. the film surface and appear to be larger compared to the size of pits reported in the literature, which may be due to the higher molecular weight employed in this study [4].

The introduction of CTAB-capped particles into the polymer blend has an evident influence on the phase morphology of the film. Fig. 7 presents representative tapping-mode AFM images of the PS-PMMA/Ag composites. Both topography (panel a) and phase (panel b) images are shown. The former shows phase separation between PS and PMMA but does not have enough resolution to figure out the Ag particle domains; however, the latter presents both the polymeric phases and $\mathrm{Ag}$ particle domains clearly. The incorporation of the $\mathrm{Ag}$ nanoparticles into the binary polymer blend system causes the disappearance of pits; instead, surface bumps are developed. The light bumps may refer to PS-rich domains [6]. The size of surface feature is reduced from 4.5 (pits) to 0.4 (bumps) $\mu \mathrm{m}$. This result can be ascribed to both the compatibilizing effect (the decrease in interfacial tension of the mixture) and the suppression of the coalescence of the domains due to the pinning effect of the localized particles. In addition, the spherical bright spots in Fig. 7 may refer to the Ag nanoparticle domains. In contrast to dispersion of the Ag particles in solvent, the particles undergo aggregation/agglomeration in polymeric medium. Both structures of the particles are called particle domains. The size of the particle domains was mainly determined by the extent of affinity of the particles surface with the surrounding polymer matrix [27]. Ag nanoparticles capped by $0.002 \mathrm{M}$ CTAB were dispersed in the matrix with $90 \mathrm{~nm}$ domains. These particle domains loosely covered by aliphatic ligands of CTAB were found to be located in the PMMA phase. When the concentration of CTAB in the course of surface functionalization was increased ten fold $(=0.02 \mathrm{M})$, CTAB molecules were denser grafting on the particle surface. The higher the density of the molecules, the smaller the particle domains [28]. The size of $\mathrm{Ag}$ particle domains was reduced to $20 \mathrm{~nm}$ and appeared to sequester at the interface of the PS bumps and continuous PMMA phase (Fig. 8). An investigation of the surface feature in the presence of pristine CTAB could offer insight about the role of CTAB in the development of the surface blend morphology. Pristine CTAB showed a milky suspension in THF, at least in the range of 0.020-0.002 M, indicating the formation of micelle-type structures that does not provide homogeneous surface modification.

The PS-PMMA/Ag composite films prepared by particles treated with $[C T A B]=0.02 \mathrm{M}$; i.e. particle domains with $20 \mathrm{~nm}$ in diameter at interface, were subjected to isothermal posttreatment at $165{ }^{\circ} \mathrm{C}$ for 3 days. Glass Transition Temperature $\left(T_{g}\right)$ of PS and PMMA is $105{ }^{\circ} \mathrm{C}$ and $104{ }^{\circ} \mathrm{C}$, respectively [29]. The heat treatment of the composites above $T_{g}$ allows the diffusion of both PS domains and organophilic Ag nanoparticles. It has to be noted that the blend was asymmetric in terms of molecular weights such that PMMA has a much lower molecular weight compared to PS. The lower molecular weight of the continuous PMMA phase has lower viscosity, which provides a fluid medium convenient for the diffusion of $\mathrm{Ag}$ nanoparticles during isothermal treatment. Upon heat treatment, the particles migrated and localized in PS-rich. (Fig. 9) In general, the particles were susceptible to coarsening at high temperature and form large domains. Not surprisingly, the mean diameter of particle domains enlarged to $60 \mathrm{~nm}$ (Fig. 10). Note that the large particle domains in PMMA-rich phase were treated with $[\mathrm{CTAB}]=0.002 \mathrm{M}$. Similar to the Ag particles, PS domains enlarged. Fig. 11 shows the size distribution of PS domains before and after post-treatment. The domains diffused and coalesced forming larger domains $(1.25 \mu \mathrm{m})$ compared to the domains developed in the presence of CTAB-capped particles at room temperature.

The wetting coefficient $\left(\omega_{a}\right)$ is a frequently used principle to predict the placement of the particles $[14,30]$. It can be derived from Young's equation: 


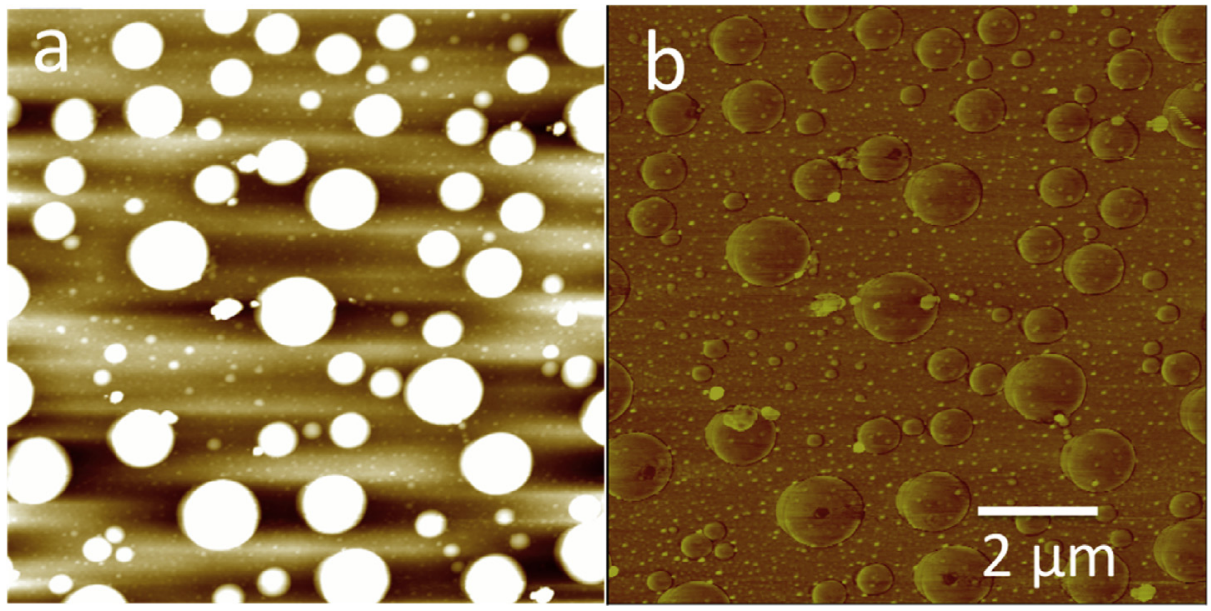

Fig. 7. Tapping mode AFM (a) topography and (b) phase image of Ag particle domains located in preferentially PMMA-rich domain. The particle domains consist of individual Ag nanoparticles capped by $0.002 \mathrm{M}$ CTAB is dispersed in the matrix with a diameter of $90 \mathrm{~nm}$. Color scale in the topography image is reduced to make the particle domains visible. Since the bumps are much larger than the particle domains, they get into shiny. On the other hand, in the phase image both features are clearly seen.

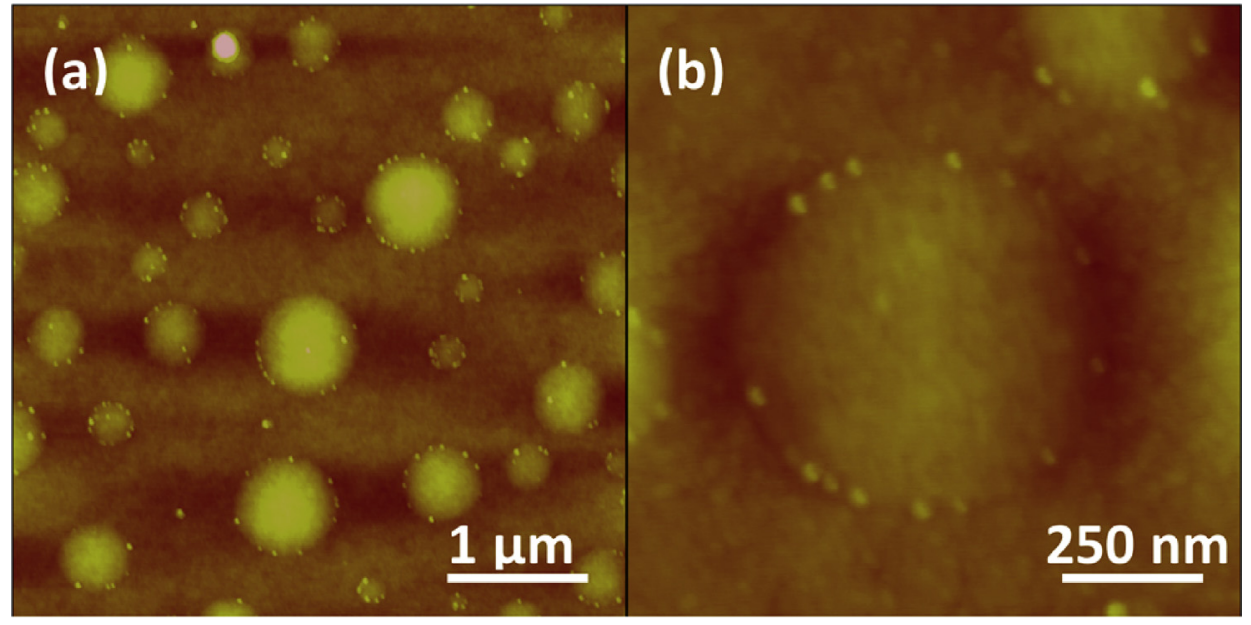

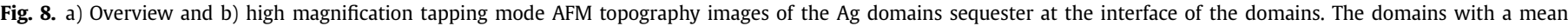
diameter of $20 \mathrm{~nm}$ consist of individual Ag nanoparticles capped by $0.020 \mathrm{M} \mathrm{CTAB}$.

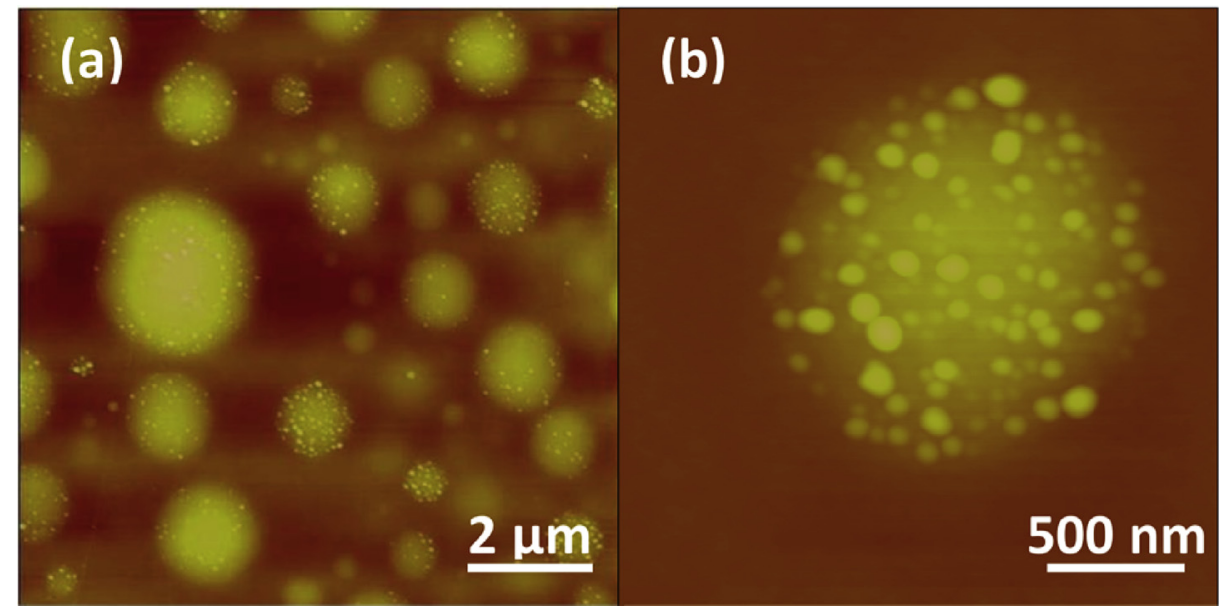

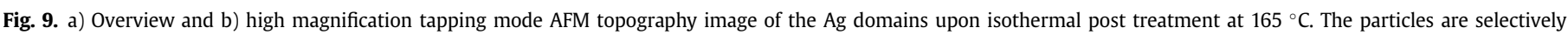
located in PS domain. The mean size of Ag particle domains is $60 \mathrm{~nm}$. 


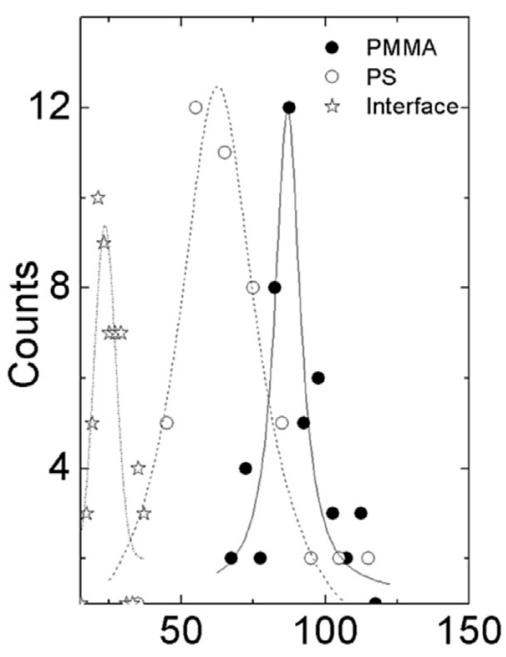

Diameter of Ag domains / $\mathrm{nm}$

Fig. 10. Size distribution of the Ag particle domains heterogeneously dispersed in PSPMMA blend films. The particles treated with $[\mathrm{CTAB}]=0.002 \mathrm{M}$ are located in PMMArich phases (mean diameter is $90 \mathrm{~nm}$ ). The ones treated with $[\mathrm{CTAB}]=0.02 \mathrm{M}$ are present at the interface of the PS-PMMA domains (mean diameter is $20 \mathrm{~nm}$ ). Postprocessing of this film at $165{ }^{\circ} \mathrm{C}$ for three days enlarges the particle domains (mean diameter is $60 \mathrm{~nm}$ ) and directs them to the PS-rich phases.

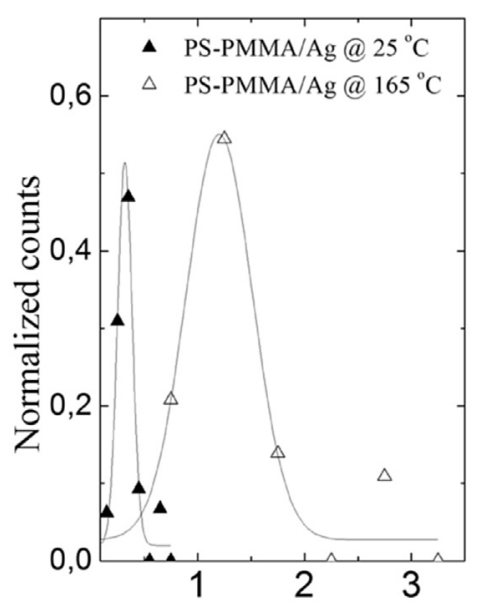

Diameter of PS Domains / $\mu \mathrm{m}$

Fig. 11. Normalized size distribution of PS domains in the composite films before and after postprocessing $\left(165^{\circ} \mathrm{C}\right)$. The size of the PS domains was measured from AFM images using section analysis option of the software.

$\omega_{a}=\frac{\gamma_{P M M A-A g}-\gamma_{P S}-A g}{\gamma_{P M M A-P S}}$

where $\gamma_{P M M A-P S}, \gamma_{P S-A g}$, and $\gamma_{P M M A-A g}$ are the interfacial tensions between PMMA and Ag nanoparticles, between PS and Ag nanoparticles, and between PS and PMMA, respectively. If $\omega_{a}>1, \mathrm{Ag}$ nanoparticles preferentially locate in the PS matrix; if $\omega_{a}<-1, \mathrm{Ag}$ nanoparticles preferentially locate in the PMMA phase; and if $-1<\omega_{a}<1$, Ag nanoparticles selectively distribute at the interface between the PS and PMMA matrix [31]. Table 1 presents interfacial energy between material components at $25^{\circ} \mathrm{C}$ and at $165^{\circ} \mathrm{C}$. The $\mathrm{Ag}$ particles are densely covered by CTAB and the literature has no evident interfacial tension values for this material combination. For this circumstance, CTAB was replaced with neat polyethylene in the calculations due to both having close chemical structures consisting of long alkyl chain and tabulated interfacial tension values. Moreover, the values of interfacial tension at different temperature were obtained by the extrapolation of the tension values assuming linear correlation between tension and temperature (Figure S2) [32]. Based on these estimations, at $25^{\circ} \mathrm{C}, \omega_{a}=0.9$ is $<1$, indicating that CTAB-capped Ag nanoparticles tend to selectively localize in continuous PMMA phase. On the other hand, at $165{ }^{\circ} \mathrm{C}, \omega_{a}=2.8$ is $>1$, and the particles preferentially located in the PS domain. These results are consistent with our results shown in the AFM images. (Figs. 7 and 9)

The location of the particles in the system also appears driven by the size of the particle domains. For instance, at $25^{\circ} \mathrm{C}$, the particles can be localized either in PMMA or at the interphase of the particle domains depending on the size of the nanoparticle domains. We can gain more insight by comparing the energy difference when a small or a large nanoparticle domain is located at the interface during the structural development $[13,33]$. The change in energy is

$\Delta E_{\text {int }}=\frac{\pi d^{2}}{4 \gamma_{P M M A-P S}}\left[\gamma_{P M M A-A g}-\gamma_{P S-A g}+\gamma_{P M M A-P S}\right]^{2}$

where $d$ is diameter of particle domains. When the particle radius is 20 and $90 \mathrm{~nm}, \Delta E_{\text {int }}$ is $3.6 \times 10^{-21}$ and $73.8 \times 10^{-21} \mathrm{~J}$, respectively. The probability of finding a nanoparticle domains at the interface at one energy state is

$f_{i}=\frac{e^{-\frac{\Delta E_{\text {int }}}{k_{B} T}}}{\sum_{i} e^{-\frac{\Delta E_{\text {int }}}{k_{B} T}}}$

where $k_{B}$ is the Boltzmann constant. The result of the calculation shows that the probability of finding a small particle $(d=20 \mathrm{~nm})$ at the interface is 9 orders of magnitude greater than the one of finding a larger particle $(d=90 \mathrm{~nm})$. In other words, the higher the energy, the lower the probability of finding the particle domains at the interface of polymeric domains. This estimation also agrees with the experimental results.

\section{Conclusions}

We have designed a composite system consisting of organophilic Ag nanoparticles and immiscible PS-PMMA blend. The particles were obtained by a reduction of $\mathrm{AgNO}_{3}$ via $\mathrm{NaBH}_{4}$. The assynthesized particles were electrostatically stabilized. Upon surface capping with CTAB in aqueous solution, the particles became sterically stabilized and organophilic to be dispersed into the PSPMMA matrix blend. Incorporating the Ag particles into the blend homogenized the mixing of the homopolymers. We demonstrated that the location of the CTAB-capped particles can be readily controlled in the host polymer blend matrix simply by varying the concentration of the capping agent on the particle surface and isothermal posttreatment of the PS-PMMA/Ag composite. This simple and versatile method for the control over internal

Table 1

The values of interfacial tension $\left(\gamma_{\mathrm{AB}}, \mathrm{mJ} / \mathrm{m}^{2}\right)$ of PS, PMMA, and CTAB-capped $\mathrm{Ag}$ nanoparticles at different temperatures.

\begin{tabular}{lrc}
\hline & $25^{\circ} \mathrm{C}$ & $165^{\circ} \mathrm{C}$ \\
\hline PS-PMMA & $3.1^{\mathrm{a}}$ & $1.4^{\mathrm{a}}$ \\
PS-CTAB & $8.2^{\mathrm{b}}$ & $5.4^{\mathrm{b}}$ \\
PMMA-CTAB & $11.1^{\mathrm{b}}$ & $9.3^{\mathrm{b}}$ \\
\hline
\end{tabular}

The values designated with ${ }^{a}$ are obtained from reference [32]. The one ${ }^{b}$ are based on estimation taking polyethylene instead of CTAB. 
microstructure can be extended to other polymer blend nanoparticle mixture systems. Two important parameters can be employed for future studies. The weight fraction of the particles employed in this study was $<1.0 \mathrm{wt}$.\% so that the particle content can be increased. Moreover, the composition of the PS-PMMA blend employed was 1:1. Different compositions of homopolymer blends with more symmetrical molecular weights can be further studied to design novel composite architectures and accordingly, unique physical properties.

\section{Acknowledgments}

The authors thank the Centre for Materials Research of Izmir Institute of Technology (IzTech) for microscopy work and AL Demirel of Koç University for his critical reading of the manuscript. MMD acknowledges the "Outstanding Young Investigator" grant of the Turkish Academy of Sciences (TÜBA-GEBIP 2013).

\section{Appendix A. Supplementary data}

Supplementary data related to this article can be found at http:// dx.doi.org/10.1016/j.matchemphys.2015.06.044.

\section{References}

[1] M.M. Demir, G. Wegner, Challenges in the preparation of optical polymer composites with nanosized pigment particles: a review on recent efforts, Macromol. Mater. Eng. 297 (2012) 838-863.

[2] M.R. Bockstaller, R.A. Mickiewicz, E.L. Thomas, Block copolymer nanocomposites: perspectives for tailored functional materials, Adv. Mater. 17 (2005) 1331-1349.

[3] J. Kao, K. Thorkelsson, P. Bai, B.J. Rancatore, T. Xu, Toward functional nanocomposites: taking the best of nanoparticles, polymers, and small molecules, Chem. Soc. Rev. 42 (2013) 2654-2678.

[4] C. Ton-That, A. Shard, D. Teare, R. Bradley, XPS and AFM surface studies of solvent-cast PS/PMMA blends, Polymer 42 (2001) 1121-1129.

[5] R.B. Thompson, V.V. Ginzburg, M.W. Matsen, A.C. Balazs, Predicting the mesophases of copolymer-nanoparticle composites, Science 292 (2001) 2469-2472.

[6] C. Huang, M. Moosmann, J. Jin, T. Heiler, S. Walheim, T. Schimmel, Polymer blend lithography: a versatile method to fabricate nanopatterned selfassembled monolayers, Beilstein J. Nanotechnol. 3 (2012) 620-628.

[7] R. De Gryse, D. Depla, D. Poelman, S. Mahieu, W. Leroy, H. Poelman, Proc. ICTF 14 RSD (2008) 2008.

[8] R. Vasireddy, R. Paul, A.K. Mitra, Green synthesis of silver nanoparticles and the study of optical properties, Nanomater Nanotechnol. 2 (2012) 1-6.

[9] V.V. Vodnik, D.K. Božanić, N. Bibić, Z.V. Šaponjić, J.M. Nedeljković, Optical properties of shaped silver nanoparticles, J. Nanosci. Nanotechnol. 8 (2008) $3511-3515$.

[10] O. Choi, K.K. Deng, N.-J. Kim, L. Ross Jr., R.Y. Surampalli, Z. Hu, The inhibitory effects of silver nanoparticles, silver ions, and silver chloride colloids on microbial growth, Water Res. 42 (2008) 3066-3074.

[11] W. Chen, A.G. Joly, J. Roark, Photostimulated luminescence and dynamics of AgI and Ag nanoclusters in zeolites, Phys. Rev. B 65 (2002) 8.

[12] Y.-N. Zhou, H. Cheng, Z.-H. Luo, A novel method for preparing Silver
Poly(siloxane-b-methyl methacrylate) nanocomposites with multiple properties in the DMF-Toluene mixture solvent, Aiche J. 59 (2013) 4780-4793.

[13] H.-j. Chung, K. Ohno, T. Fukuda, R.J. Composto, Self-regulated structures in nanocomposites by directed nanoparticle assembly, Nano Lett. 5 (2005) $1878-1882$.

[14] H. Xiu, C. Huang, H. Bai, J. Jiang, F. Chen, H. Deng, K. Wang, Q. Zhang, Q. Fu, Improving impact toughness of polylactide/poly (ether) urethane blends via designing the phase morphology assisted by hydrophilic silica nanoparticles, Polymer 55 (2014) 1593-1600.

[15] X. Cai, B. Li, Y. Pan, G. Wu, Morphology evolution of immiscible polymer blends as directed by nanoparticle self-agglomeration, Polymer 53 (2012) 259-266.

[16] C.-H. Liu, L.-K. Chiu, J.-Y. Yeh, R.C.-C. Tsiang, Making organic-inorganic nanocomposites via selective dispersion of PS-tethered $\mathrm{SiO}_{2}$ particles in polystyrene-block-polymethylmethacrylate copolymer, J. Nanomater. 2012 (2012) 2.

[17] A. Ledo-Suárez, C.E. Hoppe, M. Lazzari, M.A.L. Quintela, I.A. Zucchi, Thermal annealing as an easy tool for the controlled arrangement of gold nanoparticles in block-copolymer thin films, Nanotechnology 24 (2013) 255304.

[18] X. Pang, Y. He, B. Jiang. J. Iocozzia, L. Zhao, H. Guo, J. Liu, M. Akinc, N. Bowler, X. Tan, Block copolymer/ferroelectric nanoparticle nanocomposites, Nanoscale 5 (2013) 8695-8702.

[19] L. Cano, J. Gutierrez, A. Tercjak, Rutile TiO2 nanoparticles dispersed in a selfassembled polystyrene-block-polymethyl methacrylate diblock copolymer template, J. Phys. Chem. C 117 (2013) 1151-1156.

[20] C. Xu, K. Ohno, V. Ladmiral, R.J. Composto, Dispersion of polymer-grafted magnetic nanoparticles in homopolymers and block copolymers, Polymer 49 (2008) 3568-3577.

[21] Q. Zhang, T. Xu, D. Butterfield, M.J. Misner, D.Y. Ryu, T. Emrick, T.P. Russell, Controlled placement of CdSe nanoparticles in diblock copolymer templates by electrophoretic deposition, Nano Lett. 5 (2005) 357-361.

[22] J.J. Chiu, B.J. Kim, E.J. Kramer, D.J. Pine, Control of nanoparticle location in block copolymers, J. Am. Chem. Soc. 127 (2005) 5036-5037.

[23] L. Mulfinger, S.D. Solomon, M. Bahadory, A.V. Jeyarajasingam, S.A. Rutkowsky, C. Boritz, Synthesis and study of silver nanoparticles, J. Chem. Educ. 84 (2007) 322.

[24] Z. Sui, X. Chen, L. Wang, L. Xu, W. Zhuang, Y. Chai, C. Yang, Capping effect of CTAB on positively charged Ag nanoparticles, Phys. E Low Dimens. Syst. Nanostruct. 33 (2006) 308-314.

[25] C.J. Murphy, A.M. Gole, S.E. Hunyadi, J.W. Stone, P.N. Sisco, A. Alkilany, B.E. Kinard, P. Hankins, Chemical Sensing and Imaging with Metallic Nanorods, Chemical Communications, 2008, pp. 544-557.

[26] A. Shard, D. Teare, R. Bradley, C. Ton-That, XPS and AFM Surface Studies of Solvent-cast PS/PMMA Blends, 2001.

[27] M.M. Demir, P. Castignolles, Ü. Akbey, G. Wegner, In-situ bulk polymerization of dilute particle/MMA dispersions, Macromolecules 40 (2007) 4190-4198.

[28] M.M. Demir, K. Koynov, Ü. Akbey, C. Bubeck, I. Park, I. Lieberwirth, G. Wegner, Optical properties of composites of PMMA and surface-modified zincite nanoparticles, Macromolecules 40 (2007) 1089-1100.

[29] J. Brandrup, E.H. Immergut, E.A. Grulke, A. Abe, D.R. Bloch, Polymer Handbook, Wiley, New York, 1999.

[30] P. Pötschke, S. Pegel, M. Claes, D. Bonduel, A novel strategy to incorporate carbon nanotubes into thermoplastic matrices, Macromol. Rapid Commun. 29 (2008) 244-251.

[31] M. Sumita, K. Sakata, S. Asai, K. Miyasaka, H. Nakagawa, Dispersion of fillers and the electrical conductivity of polymer blends filled with carbon black, Polym. Bull. 25 (1991) 265-271.

[32] S. Wu, Surface and interfacial tensions of polymer melts. II. Poly (methy methacrylate), poly (n-butyl methacrylate), and polystyrene, J. Phys. Chem. 74 (1970) 632-638.

[33] P. Pieranski, Two-dimensional interfacial colloidal crystals, Phys. Rev. Lett. 45 (1980) 569. 